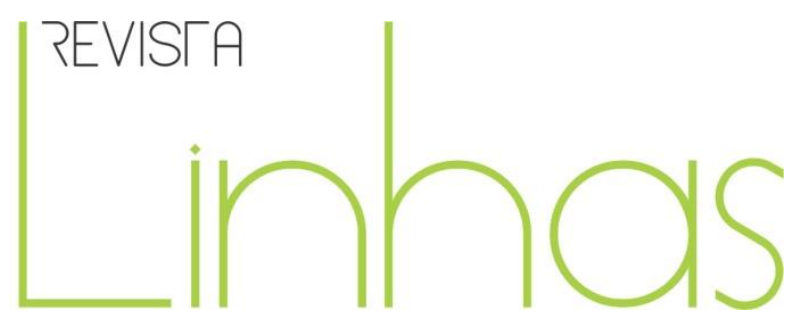

\title{
Cartilhas, pré-livros, livros de alfabetização, livros para o ensino inicial da leitura e da escrita: guardá-los e estudá-los, para quê?
}

\begin{abstract}
Resumo
Este artigo tem como objetivo principal discutir a importância da constituição de acervos de livros para o ensino inicial da leitura e da escrita, historicamente denominados de Cartas $A B C$, cartilhas, livros de leitura, pré-livros, livros de alfabetização, entre outros. Além disso, o intuito é discorrer sobre as possibilidades de pesquisas sobre e com esse artefato cultural, que é parte importante da vida escolar e, portanto, da cultura material da escola. A referência para a discussão dos aspectos mencionados é a experiência do grupo de pesquisa História da Alfabetização, Leitura e dos Livros Escolares (Hisales), vinculado à Faculdade de Educação da Universidade Federal de Pelotas (FaE/UFPel), desenvolvida desde o ano de 2006. Atualmente, com um acervo de 1488 livros didáticos para o ensino inicial da leitura e da escrita - assim denominado para justamente abarcar as diferentes denominações que tal suporte foi tendo ao longo da história -, algumas pesquisas já foram realizadas e algumas delas são aqui referidas. Desses livros, 1254 exemplares são nacionais; outros 65 exemplares são de autoria e/ou de editoras gaúchas, que estão armazenados separadamente pela natureza das pesquisas desenvolvidas no referido grupo; 43 deles são "artesanais", ou seja, feitos por professoras ou por um grupo de docente; e, finalmente, 126 livros são estrangeiros (produzidos em diferentes países e várias línguas). Acredita-se que com ações deste tipo, de guarda, preservação e pesquisa, é possível colaborar com a história da educação regional e nacional, em especial ao que se refere à história da alfabetização, da leitura e da escrita.
\end{abstract}

Palavras-chave: Acervos. Cartilhas. Pré-Livros. Livros de Alfabetização. Leitura e Escrita.

\section{Para citar este artigo:}

PERES, Eliane; RAMIL, Chris de Azevedo. Cartilhas, pré-livros, livros de alfabetização, livros para o ensino inicial da leitura e da escrita: guardá-los e estudá-los, para quê?. Revista Linhas. Florianópolis, v. 19, n. 41, p. 34-64, set./dez. 2018. 


\title{
Primers, pre-primers, textbooks for teaching reading and writing: why keep them and study them?
}

\begin{abstract}
This paper's main goal is to discuss the relevance of maintaining archives to keep early education textbooks for teaching reading and writing, usually called ABC-books, spellers, primers, pre-primers, readers, hornbooks, etc. Furthermore, we seek to debate research possibilities with and about those cultural artifacts. They are an important part of school lives, therefore, of scholar material culture. We base that debate on the experiences by the research group History of Literacy, Reading, and School Textbooks (HISALES), established within the School of Education of the Federal University of Pelotas (FaE/UFPEL) in 2006. Currently, HISALES has an archive of 1488 school textbooks for teaching reading and writing, a denomination we use to encompass all different names those materials have received throughout history. We have completed several research projects, some of which are mentioned in this paper. From those books, 1254 were edited in Brazil; additionally, 65 more are by authors from the State of Rio Grande do Sul and/or edited by publishers from the State of Rio Grande do Sul - which are archived separately given the group's research demands; forty-three books are "teacher-made", either by one teacher or by a group of teachers; finally, there are 126 foreign books (edited in different countries and in several languages). We believe that this type of action to maintain, preserve, and research those materials contributes to the history of education in our region and our country, especially the history of literacy, reading and writing.
\end{abstract}

Keywords: Archives. Primers. Pre-Primers. Alphabet Books. Reading and Writing. 


\section{Introdução}

Os livros didáticos têm ocupado um lugar central no cenário atual da pesquisa educacional ${ }^{1}$. Assim, diferentes pesquisadores têm revelado que o livro didático é um objeto cultural de natureza complexa, inscrito em uma lógica mercantil de produção e de circulação, portador de saberes considerados legítimos de serem ensinados na escola e que expressa relações de poder, uma vez que nele estão inscritos valores, ideologias, cosmovisões e perspectivas "interessadas". Conceituá-lo, inclusive, seria tarefa complexa.

Choppin (2009), historiador francês, afirma que o conceito de livro didático é relativamente recente e as variações das línguas atribuiriam certa instabilidade nas denominações e conceituações desse suporte escolar. Diz o autor que "hoje, ainda, os termos aos quais recorrem as diversas línguas para designar o conceito de livro escolar são múltiplos, e sua acepção não é nem precisa, nem estável" (CHOPPIN, 2009, p. 19). Na sequência, ele também afirma que:

Percorrendo a abundância bibliográfica científica consagrada no mundo do livro e da edição escolar, constata-se que são utilizadas conjuntamente hoje várias expressões que, na maioria das vezes, é difícil, até impossível, de determinar o que as diferenciam. Tudo parece ser uma questão de contexto, de uso, até de estilo. (CHOPPIN, 2009, p. 19)

Sendo assim, Choppin chama a atenção para a dificuldade da definição de livro didático, derivada da diversidade de vocabulário e da instabilidade dos usos lexicais (CHOPPIN, 2004, p. 549).

Para Batista (1999, p. 534), o livro didático refere-se ao livro ou impresso empregado pela escola, para o desenvolvimento de um processo de ensino ou de formação. Trata-se, pois, para o autor, de um objeto variável e instável. Desta forma, pode-se dizer que:

O termo 'livro didático' é usado - de modo pouco adequado - para cobrir uma gama muito variada de objetos portadores dos impressos que circulam na escola. Com efeito, o livro é apenas um dos muitos suportes de textos presentes na sala de aula e várias coleções didáticas assumem

\footnotetext{
${ }^{1}$ Ver, entre outros, Batista (1999); Bittencourt (2008); Cassiano (2013); Frade (2010, 2011, 2016); Frade \& Maciel (2006); Gasparello (2004); Maciel \& Frade (2004); Munakata (1997); Peres \& Tambara (2003).
} 
Assim, o livro didático pode ser considerado "como um objeto físico, ou seja, como um produto fabricado, comercializado, distribuído ou, ainda, como um utensílio concebido em função de certos usos, consumido - e avaliado - em um determinado contexto" (CHOPPIN, 2004, p. 554). É fundamental, portanto, compreender o livro didático como um artefato que é ao mesmo tempo cultural, econômico, pedagógico, textual e cujas páginas revelam intencionalidades sociais definidas, além de práticas e ideários pedagógicos de um determinado espaço e tempo históricos.

Como um "artefato de expressão humana e um bem econômico" (LUKE, 1988, p. 28), o livro didático tem uma dimensão mercantil, além de ser "um meio especializado para a introdução ritual de crianças em valores de uma cultura e conhecimento" (LUKE, 1988, p. 64).

Especificamente em relação aos livros didáticos tratados neste trabalho, quais sejam, aqueles destinados ao ensino inicial da leitura e da escrita, o livro de "introdução" da criança no universo escolar, pode-se dizer que:

Um livro para o ensino da leitura e da escrita "carrega" mais do que o método de ensino e é mais do que uma decisão e um projeto editorial: ele é, antes de tudo, um artefato de controle social, de disseminação de valores, impregnado de posições discursivas às quais crianças muito pequenas têm acesso, ao ingressar na escola. (PERES, 2014, p. 115)

Para Frade (2011, p. 184), os livros para o ensino inicial da leitura e da escrita “portam saberes relacionados ao processo de alfabetização, mas também são objetos que configuram uma cultura gráfica, constroem dispositivos de pensamento". Esses livros são representativos, segundo Maciel e Frade (2004, p. 546), de práticas e ideários pedagógicos, assim como de práticas editoriais, além disso, "historicamente, vêm se constituindo como primeira via de acesso à cultura do impresso, uma vez que em nossa sociedade grandes parcelas da população vieram constituindo suas 'bibliotecas' e seus modos de ler a partir da escola" (MACIEL; FRADE, 2004, p. 546).

Nesse sentido, coloca-se uma primeira razão para o estudo desses livros: para alguns grupos sociais eles significam o primeiro acesso ao impresso, ao objeto livro. Assim sendo, eles representam igualmente uma forma particular de inserção na cultura e uma 
via de formação moral, nacional, cívica, ética e estética. Não se trata, assim, de um objeto cultural e pedagógico isento ou neutro, cujo único objetivo é apenas ensinar as novas gerações a ler e a escrever.

Embora tendo a mesma finalidade, servir de suporte para o ensino e a aprendizagem da leitura e da escrita, esses livros didáticos têm sido nomeados de forma diferenciada, dependendo da época, das disputas pedagógicas e das propostas metodológicas sob as quais são produzidos. Nomeado de carta, cartinha, silabário, abecedário, livro de $A B C$, livro para ensino da leitura, passando por cartilha, pré-livro e, mais recentemente, livro de alfabetização, o objetivo tem sido o mesmo, embora os formatos, muitas vezes, sejam diferenciados: inserir as crianças no universo da cultura escrita, associada à formação nacional, moral e cívica.

A denominação pré-livro, por exemplo, em contraposição à cartilha e seu suposto método, o sintético, é atribuída à professora mineira Lúcia Casasanta, quando da divulgação do método global de contos, desde os anos de 1930, no Brasil (MACIEL, 2001). O uso da denominação livros de alfabetização, por sua vez, data dos anos 2000, com o advento da avaliação dos livros feita no Programa Nacional do Livro Didático (PNLD) do Ministério da Educação (MEC), também para contrapor ao uso da palavra cartilha e seu suposto atrelamento ao método silábico de ensino da leitura e da escrita.

Assim, a denominação e os formatos variaram ao longo do tempo, mas o objetivo tem sido o de introduzir as crianças e os jovens e adultos não leitores na cultura escrita, como se afirmou. Para Dietzsch (1990),

[...] ainda que diferentes em suas formas de produção e divulgação, nem as remotas 'cartas do ABC', a que se seguiram as 'cartas de sílabas', nem as cartilhas - das mais antigas às atuais - conseguiram escapar às discussões, envolvendo, essencialmente, a questão do método de alfabetização. (DIETZCH, 1990, p. 36)

Chartier, A. M. (2007, p. 69), referindo-se ao "livreto de alfabetização", afirma que se trata de um "livro de iniciação cultural", que coloca "em cena o 'mundo da escrita' proposto como referência aos leitores principiantes".

Os livros para o ensino da leitura e da escrita como "referência e iniciação cultural" devem ser estudados na sua relação com processos históricos de alfabetização e de 
escolarização, práticas de formação docente, interesses políticos e necessidades das populações, critérios e índices de acesso à cultura escrita, etc. Para Luke (1988), definir historicamente a qualidade da alfabetização envolve a reconstrução histórica do que é se tornar alfabetizado, "com base nos existentes artefatos textuais" (LUKE, 1988, p. 15). Nesse sentido, “necessariamente, deve ser uma história educacional que incida sobre os textos de escolarização de massa" (LUKE, 1988, p. 15).

Para o caso do Brasil, ao concordar com a perspectiva indicada por Luke (1998), da relação entre estudos educacionais de abordagem histórica e "textos de escolarização de massa", vários problemas se colocam. Um deles é a ausência de políticas públicas sistemáticas, contínuas e organizadas de manutenção de acervos de livros didáticos. Galvão e Batista (2003), ao se referirem à realização de pesquisas sobre manuais escolares de um modo geral, afirmam que:

No caso brasileiro, depara-se, de modo geral, com a ausência de acervos específicos de manuais escolares, o que gera, para os pesquisadores, um sobre-esforço na localização dos livros em acervos não especializados, onde não estão, via de regra, catalogados, além de gerar várias limitações à pesquisa, sobretudo no que diz respeito ao restabelecimento do circuito da produção dos livros: mesmo nos exemplares localizados, faltam referências quanto ao número e à data das edições, às tiragens, além daqueles que estão parcialmente danificados, sem capa, sem folha de rosto, etc. (GALVÃO; BATISTA, 2003, p. 172)

Nesta direção, Choppin $(2002,2004,2008,2009)$ também discorre a respeito das dificuldades e dos limites dos estudos dos livros escolares, mostrando os problemas nas pesquisas nessa área que se estendem desde a localização, a conservação, as condições materiais do objeto livro didático, até as fragilidades teóricas e metodológicas desses estudos.

O grupo de pesquisa História da Alfabetização, Leitura, Escrita e dos Livros Escolares (Hisales), vinculado ao Programa de Pós-Graduação em Educação da Faculdade de Educação da Universidade Federal de Pelotas (PPGE/FaE/UFPel)², tem procurado

\footnotetext{
${ }^{2}$ O Hisales (História da Alfabetização, Leitura, Escrita e dos Livros Escolares) é, ao mesmo tempo, um grupo de pesquisa cadastrado no CNPq desde junho de 2006 e um centro de memória, coordenado pelas professoras Dra. Eliane Peres e Dra. Vânia Grim Thies (FaE/UFPel) e reúne pesquisadores da UFPel e de outras instituições de ensino da região sul, contando com a participação de pesquisadores, de alunos de
} 
estabelecer uma política de recolha, tratamento e guarda de objetos da cultura material escolar, constituindo, assim, importantes acervos para a pesquisa educacional. O Hisales possui, atualmente, seis acervos: I) Cadernos de alunos - ciclo de alfabetização e outras séries; II) Cadernos de planejamento (Diários de classe) de professoras; III) Livros para o ensino da leitura e da escrita nacionais e estrangeiros; IV) Livros didáticos elaborados por autoras gaúchas, no Rio Grande do Sul, entre os anos de 1940 e 1980; V) Materiais didático-pedagógicos; VI) Escritas pessoais e familiares ${ }^{3}$.

Neste texto, o objetivo principal é apresentar a constituição, a organização e o propósito do acervo III supracitado, qual seja, o de "livros para o ensino da leitura e da escrita nacionais e estrangeiros". Algumas pesquisas realizadas com esses livros também são referidas, com o objetivo de indicar as potencialidades de investigações que um acervo dessa natureza possibilita.

\section{A constituição do acervo de livros para o ensino da leitura e da escrita}

Atualmente há, no acervo do Hisales, 1255 exemplares nacionais de livros para ensino da leitura e da escrita. Como a nomenclatura adotada indica, trata-se da produção didática nacional localizada e inventariada no grupo de pesquisa, produzida por diferentes autores e autoras, de diversas partes do país e publicada por distintas editoras de âmbito nacional. Além disso, há 65 exemplares de autoria de autoras e/ou editoras gaúchas, que estão armazenados separadamente pela natureza das pesquisas desenvolvidas, qual seja, compreender a produção (autoria, editoração, perspectivas políticas e pedagógicas, métodos de ensino, projetos gráfico-editoriais, etc.), a circulação e os usos desses livros para o caso do contexto específico do Rio Grande do Sul. Nesse

\footnotetext{
pós-graduação (mestrado e doutorado) e de graduação. As pesquisas realizadas pelos integrantes do grupo se inserem basicamente em três eixos de estudos, como o próprio nome do grupo indica: 1) investigações sobre a história da alfabetização e da escolarização; 2) pesquisas acerca das práticas escolares e não escolares de leitura e escrita (práticas de letramento); 3) análises da produção, circulação e utilização de livros escolares elaborados por autoras gaúchas, especialmente entre os anos de 1940-1980 (período de criação, influência e produção didática do Centro de Pesquisas e Orientações Educacionais - CPOE, vinculado à Secretaria de Educação do Estado - SEC/RS). Mais informações a respeito do Hisales, dos acervos, das ações, dos projetos de pesquisa, de ensino e de extensão, podem ser vistas via internet, no site: <http://www.ufpel.edu.br/fae/hisales/> e no perfil na rede social Facebook (Hisales).

${ }^{3}$ A constituição desses acervos se dá principalmente através de doações de materiais em qualquer estado de conservação, de pessoas e de instituições, bem como por aquisições e compras dos próprios integrantes do grupo de pesquisa.
} 
acervo, constam ainda, 43 livros nacionais, denominados de "artesanais" e 126 livros para o ensino inicial da leitura e da escrita estrangeiros (produzidos em diferentes países e várias línguas).

Identificar esses livros na sua rede de relações ou no "circuito da comunicação" (DARNTON, 2010) do qual fazem parte, constitui uma das abordagens de pesquisa realizada no grupo nos últimos anos. Darnton (2010), a partir da proposição do "circuito da comunicação", auxilia na compreensão da intrincada relação que se estabelece em torno da produção, da circulação e dos usos dos livros, pois, segundo o autor, mesmo considerando que o livro é concebido e difundido nas sociedades de formas variadas, de acordo com o lugar e a época, os livros impressos continuam passando pelo mesmo ciclo de comunicação que vai do autor ao editor (se não é o livreiro quem assume esse papel), ao impressor, ao distribuidor, ao vendedor e chega ao leitor (DARNTON, 2010, p. 125), ou ao usuário, no caso do livro didático. Segundo o autor,

[...] o circuito percorre um ciclo completo. Ele transmite mensagens, transformando-as durante o percurso, conforme passam do pensamento para o texto, para a letra impressa e de novo para o pensamento. A história do livro se interessa por cada fase desse processo e pelo processo como um todo, em todas as suas variações no tempo e no espaço, e em todas as suas relações com outros sistemas, econômico, social, político e cultural, no meio circundante. (DARNTON, 2010, p. 126)

Tais aspectos podem e devem ser considerados também no que tange às análises do livro didático. Para Chartier, R. (1990, 1996, 2000), o livro é um objeto cujo ciclo envolve as práticas de produção, de circulação e de apropriação, que são interdependentes e essenciais para o conhecimento de vários aspectos que podem ser investigados a partir desse impresso e que revelam características de criação, fabricação e formas de uso, sempre relacionadas a um contexto histórico, econômico, cultural, educacional e mercadológico. No caso dos livros didáticos, esses ciclos evidenciam a existência de etapas, técnicas e atividades humanas, que envolvem autores, editores e políticas editoriais, designers, ilustradores, impressores, mercado, tendências pedagógicas, governo, escolas, professores, alunos, entre outros. Daí advém, portanto, sua complexidade.

Coletar, guardar, inventariar e estudar os livros para ensino inicial da leitura e da 
escrita é o trabalho que tem sido realizado no Hisales desde $2006^{4}$. São desenvolvidas investigações tomando alguns desses livros como objeto de análise e que são feitas, pelo menos, sob três perspectivas: a) perspectiva contextual (autoria, editoras, políticas públicas, vinculações institucionais, etc.); b) perspectiva pedagógica (métodos e didáticas); c) perspectiva gráfico-editorial (projeto editorial e gráfico, produção gráfica, materialidade, imagens, tipografia, cores, entre outros). Os trabalhos desenvolvidos ora enfatizam uma dessas dimensões, ora combinam duas ou até as três delas de forma articulada.

$\mathrm{Na}$ sequência, apresenta-se o referido acervo, destacando suas principais características e alguns dos trabalhos já desenvolvidos. Convém salientar que, com o intuito de facilitar a organização do acervo - especialmente a distribuição física dos livros -, foi realizada uma separação em quatro diferentes conjuntos: a) Conjunto 01: livros de língua nacional (produção brasileira, excetuando os produzidos por autoras ou editoras gaúchas); b) Conjunto 02: livros de língua nacional "gaúchos" (produzidos por autoras e/ou editoras gaúchas); c) Conjunto 03: livros de língua nacional "artesanais"; d) Conjunto 04: livros estrangeiros. É com essa divisão que são apresentados os dados a seguir, comentando-se algumas das pesquisas já realizadas.

\section{a) Conjunto 01: os livros para ensino da leitura e da escrita em língua nacional}

Segundo Luke (1988), um dos primeiros passos em pesquisas que abordam o fenômeno da aprendizagem da leitura e da escrita é reunir os artefatos de alfabetização, descrevendo seus contextos e usos, sua distribuição espacial e temporal; contudo, tanto o estilo interno desses artefatos quando quem os produziu podem também ser considerados partes do contexto. Assim, começou-se a reunir esses artefatos. A Tabela 1 contém os dados que apresentam as quantidades de livros para o ensino da leitura e da escrita em língua nacional e suas décadas, totalizando 1255 exemplares, de 1910 aos dias atuais.

\footnotetext{
${ }^{4}$ Sobre as formas de localização, de identificação, de tratamento e de organização desse acervo de obras didáticas já foram produzidos dois trabalhos (PERES, 2006c; PERES; RAMIL, 2015a).
} 
Tabela 1 - Livros para ensino da leitura e da escrita em língua nacional do acervo do grupo de pesquisa Hisales

\begin{tabular}{c|c}
\hline \multicolumn{2}{c}{ LIVROS PARA ENSINO DA LEITURA } \\
E DA ESCRITA EM LíNGUA NACIONAL \\
\hline Década & Quantidade \\
\hline 1910 & 01 \\
\hline 1920 & 01 \\
\hline 1940 & 02 \\
\hline 1950 & 09 \\
\hline 1960 & 10 \\
\hline 1970 & 43 \\
\hline 1980 & 90 \\
\hline 1990 & 338 \\
\hline 2000 & 485 \\
\hline 2010 & 186 \\
\hline Sem identificação & 90 \\
\hline TOTAL & $\mathbf{1 2 5 5}$ \\
\hline
\end{tabular}

Fonte: Acervo Hisales (junho 2018).

O conjunto desses livros inclui também Manuais do Professor relativos a alguns títulos que estão contabilizados na relação supracitada. Além de disponibilizar títulos produzidos desde a década de 1910 até os dias de hoje, esse conjunto de livros evidencia dados iniciais interessantes de pesquisa. Para além do reconhecimento dos métodos didático-pedagógicos adotados em determinada época, é possível analisar a autoria desses livros, as editoras, os editores, as ilustrações, os projetos gráficos e editoriais, entre muitos outros aspectos.

Outros dados que também podem ser identificados nesses livros, independente da época em que foram publicados, referem-se aos vínculos a programas estaduais e federais de educação e convênios, pois muitos deles apresentam essa informação impressa na capa ou na contracapa ( $4^{\mathrm{a}}$ capa) e também nas páginas que integram a parte pré-textual, como forma de evidenciar, divulgar e comprovar a relação entre as editoras (setor privado) e o governo estadual e/ou federal (setor público). Esses dados costumam ser identificados na forma de selos impressos, de carimbos ou mesmo por informação escrita por extenso. Mesmo que esses dados estejam ainda em processo de coleta e 
análise, já foram encontrados registros de vínculos com programas e/ou órgãos públicos, tais como: Centro de Pesquisas e Orientação Educacional da Secretaria de Educação do Estado do Rio Grande do Sul (CPOE/RS), Comissão do Livro Técnico e do Livro Didático (Colted), Instituto Nacional do Livro (INL), Programa do Livro Didático para o Ensino Fundamental (Plidef), Programa Nacional do Livro Didático (PNLD), Programa Nacional Biblioteca da Escola (PNBE), entre outros. Encontrar essas informações impressas nos próprios livros corrobora com as pesquisas de temas afins, pois facilita a coleta de dados que poderiam ser encontrados apenas em documentos oficiais. No que diz respeito a esses vínculos, considera-se que as ideias de "Estado financiador e comprador" da produção didática e da relação entre setor privado e público são centrais nesse campo de investigação.

No Hisales, ainda há poucas investigações desenvolvidas com esse conjunto de livros. Entre as pesquisas já produzidas destaca-se a de Monks, Peres e Thies (2013) que a partir de uma amostra desse acervo (1950-2000), problematizaram os títulos desses livros. Escolhendo livros cujos títulos são, por exemplo, Caminho Suave (Branca Alves de Lima, 1979), No Reino da Alegria (Doracy de Paulo Falleiros de Almeida, 1975), Cartilha Mundo Mágico (Lídia Maria de Moraes, 1991), Porta Aberta (Isabella Carpaneda e Angiolina Bragança, 1994), entre tantos outros, as autoras concluem que "os títulos se configuram como signos ideológicos, apresentando um projeto enunciativo que se assenta em um discurso da 'passagem' de uma condição à outra na vida das crianças: a aprendizagem inicial da leitura e da escrita" (MONKS; PERES; THIES, 2013, p. 1175-1176).

Outro trabalho, de Vieira, Monks e Vieira (2013), consistiu em identificar, nos cadernos de planejamento de uma professora alfabetizadora, as cópias de atividades de cartilhas, consultando esse conjunto de livros em língua nacional para confrontar o proposto (planejado pela professora) e o existente nos livros em termos de textos e atividades. Na sequência, Vieira (2014), em sua Dissertação de Mestrado em Educação (PPGE/FaE/UFPel), ampliou o estudo a partir dos cadernos de planejamento dessa professora alfabetizadora (23 cadernos do período de 1983-2000), no qual identificou o uso das cartilhas, através das recorrências de títulos, atividades desenvolvidas, reproduções e adaptações de páginas, entre outros, no processo de alfabetização. Recorreu ao acervo para confrontar os planejamentos das professoras com os livros 
mencionados e/ou identificados (sem menção explícita), analisando o prescrito (livro didático) e o processo de "transposição didática".

No artigo produzido por Peres, Vahl e Thies (2016), as autoras analisaram uma das mais importantes cartilhas brasileiras, considerada o best-seller da alfabetização brasileira, qual seja: Caminho Suave ${ }^{5}$. Publicada pela primeira vez em 1948 por Branca Alves de Lima, a cartilha continua sendo publicada até os dias atuais e já vendeu mais de 40 milhões de exemplares no Brasil. Nesse estudo, as autoras apresentam dados de produção e circulação e, também, abordam os aspectos pedagógicos, especialmente no que concerne ao método adotado, o silábico, além da proposição da autora da “Alfabetização pela Imagem”.

Sobre essa mesma cartilha e o conjunto de materiais de apoio associada a ela (baralho, cartazes, carimbos), Peres e Ramil (2015b, 2015c) desenvolveram uma análise em uma perspectiva gráfico-editorial, abordando as imagens e as características do projeto gráfico desses livros. Através dessa pesquisa, foi possível identificar que, devido às variações estéticas das ilustrações características de determinados períodos, dos avanços de tecnologias gráficas e de impressão, além das modificações necessárias decorrentes de sucessivas reflexões conceituais e regras ortográficas, a Cartilha Caminho Suave e o Material de Apoio passaram por significativas modificações nas suas reedições. Isso foi identificado através das alterações de aspectos gráficos, estilos, imagens, cores, tipografia, formato, acabamento, palavras-chave utilizadas, entre outros ${ }^{6}$. As mesmas

\footnotetext{
${ }^{5} \mathrm{O}$ acervo guarda nove exemplares da cartilha Caminho Suave, que são: Cartilha Caminho Suave (três exemplares de mesmo ano e edição: 1979, $81^{a}$ ed.); Cartilha Caminho Suave - Renovada e ampliada (seis

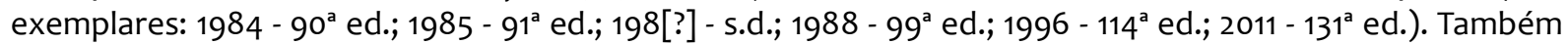
são encontrados os seguintes itens da Série Didática Caminho Suave: $1^{\circ}$ Livro de Leitura Caminho Suave (um exemplar: $1982-22^{\mathrm{a}}$ ed.); Comunicação e Expressão - $1^{\text {a }}$ Série $/ 1^{\circ}$ Grau Caminho Suave (dois exemplares:

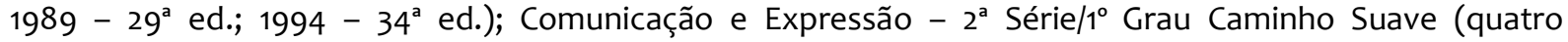
exemplares: $1984-13^{\mathrm{a}}$ ed. ( 1 item); $1993-26^{\mathrm{a}}$ ed. (3 itens); Comunicação e Expressão - $4^{\mathrm{a}}$ Série $/ 1^{\circ} \mathrm{Grau}$ Caminho Suave (um exemplar: $1996-22^{\mathrm{a}}$ ed.); Manual do Professor para a cartilha Caminho Suave (dois exemplares: $1979-3^{\mathrm{a}}$ ed.; s.d. $-7^{\mathrm{a}}$ ed.); Manual do Professor para a cartilha Caminho Suave - Renovada e ampliada (três exemplares: s.d. $-7^{\mathrm{a}}$ ed. ( 2 itens); s.d. $-8^{\mathrm{a}}$ ed.); Manual do Professor para $01^{\circ}$ Livro Caminho Suave (um exemplar: $1979-2^{\mathrm{a}}$ ed.); Caligrafia Caminho Suave (um exemplar: $2015-1^{\mathrm{a}}$ ed.). Quanto ao Material Audiovisual (nomenclatura da década de 1970) / Material de Apoio (nomenclatura da década de 1980, o acervo possui: um conjunto de cartazes de "Alfabetização pela Imagem" (sem data); uma caixa de carimbos didáticos de "A Família" - Caminho Suave (sem data); dois kits de Testes de "Alfabetização pela Imagem"/Baralhinhos Didáticos da Cartilha, de épocas distintas (um mais antigo e outro da década de 2000); Diplomas - inseridos nas cartilhas (datas variadas). Dados de 21/09/2017.

${ }^{6}$ Alguns dos autores que subsidiaram essas análises foram Panofsky (1986), Miranda (2015), Fernandes (2003), Lupton e Phillips (2008), Clair e Busic-Snyder (2009), Fuentes (2006), entre outros.
} 
autoras (PERES; RAMIL, 2018) também produziram um artigo no qual identificam os diferentes tipos de usos da mesma cartilha nas escolas gaúchas, a partir de uma análise realizada nos cadernos de alunos em fase de alfabetização que integram outro acervo localizado no Hisales. As autoras concluíram, entre outros aspectos, que:

[...] a utilização longeva da cartilha Caminho Suave incluiu recortes de páginas ou partes das páginas, reprodução fotocopiada e mimeografada, desenhos reproduzidos por cópia ou recriação, adaptações de lições, criação de novas e diferentes atividades tendo por base a cartilha.

Se em relação ao conteúdo pode-se verificar isso - as cópias de lições e as adaptações variadas - do ponto de vista de um modelo gráfico-editorial a Caminho Suave também foi e tem sido paradigmática. Todo um fazer gráfico foi apropriado pelas alfabetizadoras, reproduzido por elas, ensinado aos alunos e por eles também aprendido e dominado, na relação cartilha-quadro-caderno. (PERES; RAMIL, 2018, p. 129-130)

Salienta-se, também, que nesse acervo está guardado um único exemplar de Carta de $A B C$. Embora a ideia que se tenha é a de que, via de regra, as Cartas de $A B C$ foram usadas no século XIX, o exemplar do acervo revela que esse foi um fenômeno que se estendeu pelo século XX, com importantes empresas publicando esse tipo de material. A que está sob a guarda do Hisales é de 1924, e trata-se de Carta de ABC, para uso das escolas brasileiras, de autoria de Antonio Maria Barker ${ }^{7}$, publicado pelas Officinas da Livraria Commercial $^{8}$, de Pelotas e Rio Grande, de Meira \& C. O exemplar possui 19 páginas e segue o formato e a proposta de ensino (soletração) das Cartas para ensino da leitura e da escrita: reprodução do alfabeto, maiúsculo e minúsculo, com letra imprensa e "de mão"; seguido das "cartas de syllabas", oito cartas - páginas - com diferentes combinações de sílabas; das “cartas de palavras”, listas de palavras, quatro ao todo, nas quais as mesmas eram separadas por hífen para a soletração; e, por fim, a "carta para soletrar", constituída de frases, cujas palavras são separadas em sílabas pelo hífen, com frases de máximas religiosas e morais.

Considera-se que os livros para ensino da leitura e da escrita, que estão reunidos

\footnotetext{
7 Antonio Maria Barker nasceu em Porto/Portugal, em 1792, e morreu no Brasil em 1853. Nas palavras de Silva (2014), foi diretor do Colégio de instrução primária de meninos internos e externos e autor de uma coleção de compêndios.

${ }^{8}$ Segundo Arriada (2012), a Livraria Commercial foi fundada em 1885 em Pelotas e sua razão social era Souza Lima \& Meira. No ano de 1900, Francisco Meira tornou-se seu único proprietário. Durante muito tempo, a Livraria editou e publicou muitas obras didáticas.
} 
no acervo, precisam ser ainda melhor explorados em diferentes pesquisas, com variados focos e perspectivas analíticas. Entende-se que essa é uma tarefa que precisa ser realizada de forma coletiva e de maneira inter e transdisciplinar para qualificar as análises.

No próximo item, é apresentado o conjunto dos livros "gaúchos" para o ensino da leitura e da escrita em língua nacional.

\section{b) Conjunto 02: os livros "gaúchos" para ensino da leitura e da escrita em língua nacional}

Ao identificar a vasta e importante produção didática do Rio Grande do Sul desde o século XIX e, especialmente ao verificar o grande número de coleções de livros didáticos produzidas por autoras gaúchas entre os anos de 1940 e 1980, o interesse e o estudo por esse fenômeno impôs-se paulatinamente nos objetivos de pesquisa do Hisales ${ }^{9}$ e perguntou-se: por que o estado do Rio Grande do Sul foi um importante polo de produção didática desde o final do século XIX? Como o estado se consolidou como um grande produtor de livros didáticos? Quem produzia esses livros no Rio Grande do Sul? Qual a importância das editoras gaúchas (Selbach, Tabajara, Globo, Tomatis, etc.) no desenvolvimento dessa produção? Quais eram os profissionais envolvidos na produção e editoração dos livros didáticos no estado gaúcho? Sob quais influências teóricas e metodológicas os autores e autoras produziam suas obras? Quais as relações do mercado de livros didáticos com outros espaços públicos e privados do estado e de fora dele? Essas, entre outras, são questões que têm constituído nossas pesquisas, especialmente em relação às cartilhas e pré-livros produzidos no estado do Rio Grande do Sul, principalmente ao verificar a relação entre esses livros e aqueles produzidos nos Estados Unidos no mesmo período, qual seja, anos 60 e 70 do século XX (PERES, 2014).

Sobre a produção regional de livros didáticos, Tambara (2002) afirma que muitas províncias consolidaram, no final do século XIX, um sistema editorial autônomo após um período de controle português, francês e sob o domínio do Município da Corte. Sobre esse fenômeno no estado gaúcho, diz o autor que na década de 80 e 90, do século XIX, consolidou-se um parque editorial no Rio Grande do Sul e havia uma gama de autores que

\footnotetext{
${ }^{9}$ No final dos anos de 1990, antes mesmo do cadastramento, na base de dados do CNPq, do grupo de pesquisa Hisales, em 2006, já haviam sido realizados estudos sobre as cartilhas gaúchas (PERES, 1999).
} 
praticamente monopolizavam a produção de livros escolares. Pode-se afirmar, contudo, que essa é uma realidade que se manteve até meados dos anos de 1970 para a realidade gaúcha. Isso vale para a produção de livros didáticos em geral e aos destinados especificamente ao ensino da leitura e da escrita, principal foco das pesquisas desenvolvidas no Hisales.

Esses livros ajudam a identificar os complexos e variados aspectos que explicam as mudanças e as permanências no ensino da leitura e da escrita em nível local, bem como na identificação da autoria dessas cartilhas e nas trajetórias individuais, profissionais e institucionais dos autores e autoras de livros no estado gaúcho. Vale destacar que se trata de um material difícil de ser obtido, especialmente em razão do período de sua produção (final do século XIX até final dos anos de 1970).

No acervo de livros para o ensino da leitura e da escrita, o conjunto de livros "gaúchos" é formado, atualmente, por 29 títulos (entre as décadas de 1900 e 1970) e 65 exemplares (este número se refere aos títulos repetidos e/ou de edições e anos diferentes), como consta na Tabela 02.

Tabela 2 - Livros "gaúchos" para ensino da leitura e da escrita em língua nacional do acervo do grupo de pesquisa Hisales

\begin{tabular}{|c|c|}
\hline \multicolumn{2}{|c|}{$\begin{array}{l}\text { LIVROS PARA ENSINO DA LEITURA E DA ESCRITA EM LÍNGUA } \\
\text { NACIONAL: "GAÚCHOS" }\end{array}$} \\
\hline Década & Quantidade \\
\hline 1900 & 02 \\
\hline 1910 & 01 \\
\hline 1920 & 04 \\
\hline 1930 & 04 \\
\hline 1940 & 02 \\
\hline 1950 & 04 \\
\hline 1960 & 15 \\
\hline 1970 & 29 \\
\hline Sem identificação & 04 \\
\hline TOTAL & 65 \\
\hline
\end{tabular}

Fonte: Acervo Hisales (maio 2018). 
Desse conjunto decorre o maior número de pesquisas já realizadas no Hisales. Os estudos são focados na identificação das autoras desses livros - fundamentalmente mulheres-professoras -, na compreensão de suas trajetórias, nas relações que estabeleciam com os órgãos educacionais públicos do estado e com as editoras, nas suas proposições teóricas e metodológicas, nas suas posições ideológicas e políticas, entre outros. Para além do texto do livro (de seu conteúdo), os esforços, nessas pesquisas, têm sido, também, para compreender o contexto de produção desse material e as intrincadas e complexas relações que são estabelecidas na produção, divulgação e circulação do livro.

As pesquisas com as cartilhas e pré-livros "gaúchos" incidem especialmente sobre a produção (autorias, editoras, projetos pedagógicos, projetos gráficos, vinculação com programas oficiais do estado e do país, etc.), a circulação e os usos (identificados principalmente em cadernos de alunos e de professoras, além de entrevistas). As principais contribuições desses estudos foram identificar e inventariar essa produção didática; biografar a vida das professoras-autoras, antes silenciadas na história da educação gaúcha; demonstrar o processo de profissionalização dessas autoras; identificar profissionais envolvidos na produção do livro, como autores, editores e assessores, diagramadores, designers, ilustradores, arte-finalistas, revisores, impressores e técnicos gráficos; evidenciar relações políticas e pedagógicas; revelar a circulação das ideias sobre o ensino da leitura e da escrita no Rio Grande do Sul, inclusive na sua relação com outros estados brasileiros (especialmente Minas Gerais) e com outros países (Uruguai e Estados Unidos, por exemplo); identificar os métodos e paradigmas de alfabetização em evidência em diferentes momentos da história da educação gaúcha; analisar o papel das editoras locais no incremento da produção didática; estabelecer as relações entre os setores privado e público; indicar as relações entre as autoras e as editoras com programas locais e nacionais de livros didáticos e com órgãos públicos; explicitar disputas ideológicas em torno da alfabetização e da escolarização das crianças; apresentar projetos de formação do cidadão brasileiro e gaúcho, etc. De alguma forma, esses aspectos indicam respostas à questão colocada no título deste artigo.

Várias das pesquisas que vêm sendo realizadas inserem-se em uma abordagem considerada contextual, uma vez que se procura fazer análises que "saem do texto", 
configurando-se como uma perspectiva "extratextual", pois se procura compreender as intrincadas relações que são estabelecidas na produção de um livro, nesse caso, didático. Com essas investigações procura-se, se não analisar o circuito completo da comunicação, pelo menos parte dele (DARNTON, 2010, p. 125).

Os resultados dessas investigações foram publicados em diversos trabalhos dos integrantes do Hisales, tais como artigos, dissertações e teses ${ }^{10}$. Neles foram analisadas a trajetória das autoras e as cartilhas produzidas por importantes professoras-autoras gaúchas como, por exemplo, Nelly Cunha, Cecy Cordeiro Thofhern, Teresa Iara Palmini Fabretti, Zélia Maria Sequeira de Carvalho, Gilda de Freitas Tomatis; a circulação transnacional de ideias pedagógicas e a adoção do método de palavras no Rio Grande do Sul, especialmente com a adaptação, em 1924, da cartilha uruguaia Queres Ler, de Olga Acauan e Branca Diva Pereira; a ampla divulgação e adoção do método global de contos no estado e a produção de cartilhas congêneres, em especial Sarita e seus amiguinhos, de Cecy Cordeiro Thofehrn e Jandira Cárdias Szechir; o papel do Centro de Pesquisas e Orientações Educacionais (CPOE) na produção didática e a vinculação das autoras com esse Centro; as características e as relações editoriais, associadas às políticas públicas, nos casos de publicações, além de autoria e editoras de origem "gaúcha" (Tabajara, Selbach, Globo, entre outras); a circulação e a utilização dos livros para o ensino da leitura e da escrita nas escolas; as experiências práticas e as viagens de estudos das professorasautoras, em especial aos Estados Unidos, entre as décadas de 1950 e 1970, para aprender a fazer "bons livros didáticos"; as fortes e explícitas influências norte-americanas no campo da alfabetização escolar gaúcha, em especial na produção de cartilhas, com a adoção do método da word-recognition, mostrando que para além do método e do modelo de livro escolar, as autoras e as editoras reproduziram igualmente um projeto social nas páginas desses livros (PERES, 2014), entre outros.

Sob a perspectiva gráfico-editorial, foram realizadas pesquisas da coleção didática Tapete Verde, de autoria das professoras Nelly Cunha e Teresa lara Palmini Fabretti, publicada pela Editora Globo, de origem gaúcha. Além disso, há trabalhos envolvendo

\footnotetext{
${ }^{10}$ Entre eles estão: Peres (1999, 2003; 2006a, 2006b, 2006c; 2008a, 2008b, 2014); Peres e Porto (2004); Facin (2008); Facin e Peres (2006a, 2006b, 2007, 2008); Peres e Facin (2010); Dietrich e Peres (2006); Peres e Dietrich (2006, 2010); Dietrich (2011; 2012); Peres, Vahl e Ramil (2013); Vahl, Vieira, Ramil e Borges (2014); Vahl, Vieira e Peres (2014); Michel, Peres e Nogueira (2013); Ramil (2014a, 2018), Peres e Ramil (2015d).
} 
cartilhas de outra editora gaúcha, neste caso a Tabajara, que têm como foco específico a análise das imagens, como foi o caso do estudo da Cartilha do Guri, de autoria de Rosa M. Ruschel, Flavia E. Braun e Elbio N. Gonzalez, que integra a Coleção Guri11.

Central nas análises desenvolvidas junto ao Hisales, esse conjunto de 65 exemplares reunidos com esforço e dificuldade, ainda precisa ser melhor explorado, sob diferentes abordagens. Compreende-se que é fundamental inventariar essa produção, embora não seja suficiente. Assim, o intuito do grupo de pesquisa é avançar, em projetos colaborativos, nas pesquisas que tomam esses livros como objeto de investigação.

A seguir, apresenta-se o conjunto específico dos materiais "artesanais" para o ensino da leitura e da escrita em língua nacional.

\section{c) Conjunto 03: Os livros "artesanais" para ensino da leitura e da escrita em língua nacional}

Entre as doações feitas ao grupo de pesquisa Hisales, estão aquelas cartilhas que se convencionou denominar de "artesanais", por se tratarem de suportes para o ensino da leitura e da escrita produzidos fora do circuito editorial, confeccionadas por professoras e/ou alunos, instituições escolares, gráficas ou editoras locais e/ou "independentes". Por isso, optou-se por manter essas produções em um conjunto específico para essas ocorrências. Quando um professor ou professora ou um grupo de docentes diz: "Nós fizemos uma cartilha", indicam certo descontentamento com o material existente - produzido em grande escala e no circuito das grandes editoras - para o ensino da leitura e da escrita. Esse é o primeiro passo para uma produção própria, de caráter mais local e artesanal.

Esse fenômeno revela que historicamente têm sido produzidos suportes impressos (em pequenas gráficas ou editoras), fotocopiados, mimeografados ou até mesmo manuscritos para a alfabetização de crianças, jovens e adultos. Trata-se de um fato recorrente na história da alfabetização. Os estudos de Frade $(2010,2011,2016)$ têm mostrado a multiplicidade de materiais, manuscritos e impressos, em diferentes suportes,

\footnotetext{
${ }^{11}$ Essas investigações consistem em reunir aspectos extraídos da análise do projeto gráfico e da produção gráfica desses livros (RAMIL, 2013a; 2013b; 2014b; 2015a), assim como analisar as imagens desses suportes, através dos recursos de iconografia e iconologia (RAMIL, 2015b; 2018).
} 
usados na escola brasileira desde o século XIX. Não são apenas livros impressos que professores e professoras usam para ensinar os alunos a ler e a escrever. O uso de tábuas, tabelas, cartazes, traslados, folhetos, cartas pessoais, documentos oficiais, textos religiosos, Cartas $A B C$, murais, silabários, cartas de nomes, livros manuscritos, entre outros, foram historicamente utilizados na alfabetização das crianças.

O exemplo mais significativo desse fenômeno se expressa em um exemplar de uma cartilha manuscrita localizada no acervo do Hisales. Obra singular e rara, o livro manuscrito é de autoria de um professor - Bertone - e na capa está intitulado de Methodo, nas primeiras páginas, contudo, é assim identificado: Methodo simultâneo per la lettura e scrittura Portughese - Prof. P. Bertone, 1902 - Curral Alto - RGS. Os primeiros dados da investigação, em andamento, acerca desta cartilha e de seu autor, indicam que o professor-autor era médico, imigrante italiano, diplomado em Medicina, em 1900, pela Real Universidade de Módena e que exerceu sua atividade no município de Rio Grande/RS ${ }^{12}$.

Para além disso, o conjunto de cartilhas artesanais - manuscritas, mimeografadas, fotocopiadas ou impressas em gráficas e editoras locais e/ou "independentes" - é composto de 43 exemplares, produzidos desde a década de 1900 até os dias de hoje. Esses dados podem ser conferidos na Tabela 3.

Tabela 3 - Livros para ensino da leitura e da escrita em língua nacional "artesanais" do acervo do grupo de pesquisa Hisales

\begin{tabular}{c|c}
\hline $\begin{array}{c}\text { LIVROS PARA ENSINO DA LEITURA E DA ESCRITA } \\
\text { EM LÍNGUA NACIONAL: “ARTESANAIS” }\end{array}$ & Quantidade \\
\hline Década & 01 \\
\hline 1900 & 01 \\
\hline 1960 & 01 \\
\hline 1970 & 08 \\
\hline 1980 & 06 \\
\hline 1990 & 07 \\
\hline 2000 & 02 \\
\hline 2010 &
\end{tabular}

\footnotetext{
${ }^{12}$ Extraído de: <http://www.muhm.org.br/index.php?formulario=biografias\&metodo=4\&id=0\&submenu=4>. Acesso em: 03 jul. 2012.
} 


\begin{tabular}{c|c}
\hline $\begin{array}{c}\text { LIVROS PARA ENSINO DA LEITURA E DA ESCRITA } \\
\text { EM LÍNGUA NACIONAL: “ARTESANAIS" }\end{array}$ \\
\hline Sem identificação & 17 \\
\hline TOTAL & 43 \\
\hline
\end{tabular}

Fonte: Acervo Hisales (maio 2018).

Com relação às pesquisas realizadas com alguns desses exemplares, há, até o momento, apenas o trabalho de Kurz (2006) que utilizou esses livros "artesanais" como objeto de estudo para compreender o que e como as professoras ressignificam as orientações e os currículos oficiais em sala de aula e "confeccionam" seus próprios materiais de ensino, conforme suas experiências práticas e suas convicções pedagógicas. Embora não tenha sido muito explorado nas pesquisas desenvolvidas até o momento, destaca-se que esse conjunto de livros "artesanais" é um material bastante rico e disponível para diferentes investigações, especialmente as que problematizam a ação docente no cotidiano da escola.

Por fim, no último conjunto a ser tratado, são mostrados os dados referentes aos livros para o ensino da leitura e da escrita em língua estrangeira.

\section{d) Conjunto 04: os livros para ensino da leitura e da escrita em língua estrangeira}

Como afirmado anteriormente, o Hisales também possui um acervo de livros para ensino da leitura e da escrita em língua estrangeira, que são adquiridos pelos integrantes do grupo ou através de doações e de trocas realizadas com pesquisadores de outros países interessados na temática (dos primers) ${ }^{13}$.

Atualmente, o acervo de livros para ensino da leitura e da escrita em língua estrangeira está constituído por 126 exemplares, de 23 línguas e 04 não identificadas, como mostra a Tabela 4, com as quantidades de cartilhas especificadas por língua, tendo sido essa a opção encontrada para a catalogação e a organização física desse conjunto de

\footnotetext{
${ }^{13}$ Trocas foram feitas especialmente com integrantes do grupo Reading Primers Special Interest Group (RP$\mathrm{SIG}$ ), com sede na Alemanha, e que reúne pesquisadores do mundo todo, em especial do norte da Europa. Trata-se de um grupo ligado à International Society for Historical and Systematic Research on Schoolbooks ${ }^{13}$. Através do intercâmbio entre o Hisales e o referido grupo alemão, também já foi publicado um artigo em um catálogo organizado pelo RP-SIG (PERES; ARRIADA, 2011).
} 
livros. Salienta-se que eles são datados majoritariamente no século XX.

Tabela 4 - Livros para ensino da leitura e da escrita em língua estrangeira pertencentes ao acervo do grupo de pesquisa Hisales

\begin{tabular}{|c|c|}
\hline \multicolumn{2}{|c|}{$\begin{array}{l}\text { LIVROS PARA O ENSINO DA LEITURA E DA ESCRITA EM LÍNGUA } \\
\text { ESTRANGEIRA }\end{array}$} \\
\hline Língua & Quantidade \\
\hline Inglês & 32 \\
\hline Alemão & 14 \\
\hline Espanhol & 12 \\
\hline Línguas locais das Ilhas Papua Nova Guiné & 11 \\
\hline Russo & 07 \\
\hline Dinamarquês & 07 \\
\hline Francês & 04 \\
\hline Finlandês & 04 \\
\hline Letão & 03 \\
\hline Lituano & 03 \\
\hline Português (Portugal) & 03 \\
\hline Italiano & 02 \\
\hline Árabe & 02 \\
\hline Holandês & 02 \\
\hline Basco & 01 \\
\hline Hindi & 01 \\
\hline Chinês & 01 \\
\hline Faroese (Ilhas Faroes, Dinamarca) & 01 \\
\hline Estoniano (Estônia) & 01 \\
\hline Livoniano (Estônia) & 01 \\
\hline Sueco & 01 \\
\hline Irlandês & 01 \\
\hline Bilíngue & 08 \\
\hline Não identificadas & 04 \\
\hline TOTAL & 126 \\
\hline
\end{tabular}

Fonte: Acervo Hisales (setembro 2016).

Com relação a esses livros de origem estrangeira, os mesmos ainda não foram devidamente estudados, por serem de um conjunto relativamente recente no acervo do Hisales. Além disso, o fato de serem livros em variadas línguas torna o trabalho difícil e demorado, principalmente em função da dificuldade de tradução das informações 
textuais e da necessidade de uma compreensão mínima das línguas - algumas em extinção, como indicam os prefácios bilíngues de algumas obras -, visto que algumas análises dependem desses dados esclarecidos. Até o momento, esses livros foram explorados brevemente e há dois trabalhos publicados: o estudo de uma cartilha alemã que circulou no Rio Grande do Sul (PERES; ARRIADA, 2011), além de artigo produzido pelas pesquisadoras Thies e Vieira (2015), no qual apresentam e caracterizam os exemplares desse conjunto de livros em uma perspectiva mais descritiva.

Em relação a esse conjunto de livros, considera-se que uma das possibilidades seria uma pesquisa de abordagem transnacional, especialmente inspirada nas problematizações de Mollier (2016), o que permitiria compreender as circulações, as trocas, as variações, as similaridades, as adaptações, as traduções, as falsificaçõos, etc. Para Mollier (2016, p. 56), “a abordagem transnacional e transcultural dos fenômenos é sem dúvida a melhor garantia contra o risco de reclusão ou cegueira que espreita todo pesquisador cujo objeto é proteiforme".

Apresentou-se, assim, neste artigo, um panorama geral sobre o acervo de livros para o ensino da leitura e da escrita pertencentes ao grupo de pesquisa Hisales, bem como suas especificidades, identificando também algumas das pesquisas já efetivadas e presumindo que novas possibilidades podem ser exploradas em investigações futuras. Ainda há muito a ser feito, considerando-se o significativo acervo constituído e a pluralidade de abordagens existentes no campo da pesquisa com e sobre livros didáticos em geral e, especificamente, aqueles produzidos para ensinar os alunos a ler e a escrever.

\section{Considerações finais}

É importante registrar que, atualmente, os acervos do grupo de pesquisa Hisales estão entre os de maior relevância na área de alfabetização em nível nacional. Apesar das limitações do trabalho, a recolha, a manutenção, a catalogação, a conservação e a preservação dos materiais são realizadas com grande empenho e convicção de sua importância no campo científico. Para além de guardar e preservar a memória e a história da educação em geral e da alfabetização em específico, o intuito é o desenvolvimento de pesquisas que compreendam a produção, a circulação e os usos desses importantes 
suportes escolares, os livros didáticos.

No caso específico dos livros para o ensino inicial do ler e do escrever, o título deste artigo ajuda a compreender algumas das dificuldades das pesquisas com e sobre esse suporte. Elas começam na sua denominação e conceituação. Mais do que isso, não se trata apenas de "colocar a mão" nesse material, mas de cuidar para guardar, inventariar, organizar e, principalmente, pesquisá-lo, ou seja, saber propor questões adequadas e potenciais para investigação. As dificuldades colocam-se já no momento da recolha, seleção, tratamento e guarda desses livros. Mas não param aí. Para além disso, constantemente se indaga: do que se trata quando se fala de cartilhas, de pré-livros, de livros de alfabetização? Eles nomeiam o mesmo objeto? Objetos diferentes? Assim, além de reconhecer que historicamente há uma diversidade de matérias - que não o códice usadas no ensino da leitura e da escrita, o próprio livro utilizado nesse caso não se caracteriza como homogêneo, único e invariável.

Uma decisão tomada no Hisales, não sem antes estudar e discutir, foi a de denominar esse acervo de "livros para ensino da leitura e da escrita". Deseja-se, assim, referir-se ao ensino inicial, ao primeiro livro, ao livro de iniciação, de introdução, aquele do primeiro contato dos alunos com o universo sistematizado das letras. Isso ajuda na organização do acervo, mas não resolve alguns dos problemas, ao contrário, coloca outros como, por exemplo, guardar e pesquisar apenas o livro da $1^{\mathrm{a}}$ série $/ 1^{\circ}$ ano, apenas os primeiros livros, as cartilhas? Há, por exemplo, série de leituras graduadas, livros de leitura $\left(2^{\circ}, 3^{\circ}, 4^{\circ}, 5^{\circ}\right.$ livros). Trata-se de livros para o ensino da leitura e da escrita? Se a resposta for sim, alteram-se conjuntos de livros no acervo; se não, admite-se, entre muitas outras coisas, que primeiro “ensina-se a ler para depois ler". Daí o próprio conceito de alfabetização e/ou de ensino da leitura e da escrita está em xeque. Ou seja, os problemas são temporariamente resolvidos e sempre se colocam outros problemas, com soluções provisórias que indicam a necessidade de novas discussões que implicam debates conceituais e teóricos, além de decisões políticas. Mas não seria essa mesma a dinâmica de um acervo e da pesquisa científica?

Para finalizar, acredita-se que mesmo que parcialmente, a provocação do título deste artigo, qual seja, Cartilhas, pré-livros, livros de alfabetização, livros para o ensino inicial da leitura e da escrita: guardá-los e estudá-los, para quê?, já foi respondida. Contudo, 
ainda são retomadas as ideias de que estudar livros didáticos, em geral ou específicos, como no caso aqui indicado, permite, entre outras coisas, evidenciar projetos sociais, formas de controle social, relações de poder, mudanças e permanências históricas, processos de escolarização, políticas educacionais, concepções de conhecimento, práticas de formação humana, práticas escolares, visões de infância, projetos de alfabetização, etc. Uma imagem ou um conjunto delas, as palavras, as frases, os textos, uma página, muitas páginas, um livro, alguns livros, um conjunto deles... podem dizer muito de uma nação, de um povo, de uma cultura, de um governo, das escolas, das professoras e professores, dos alunos! É preciso saber interpretar, ter ferramentas teóricas e metodológicas adequadas e indagar correta e curiosamente esse objeto de investigação. Tais argumentos parecem suficientemente fortes para o reconhecimento da necessidade e da importância de tal empreendimento: guardar e estudar os livros didáticos. 


\section{Referências}

ARRIADA, Eduardo. Livrarias e Editoras no Rio Grande do Sul: o campo editorial do livro didático. In: REUNIÃO ANUAL DA ASSOCIAÇÃO NACIONAL DE PÓS-GRADUAÇÃO E PESQUISA EM EDUCAÇÃO - ANPED, 35ª , 2012, Porto de Galinhas/PE. Anais... Porto de Galinhas: UFPE, 2012, p. 01-17.

BATISTA, Antonio Augusto Gomes. Um objeto variável e instável: textos, impressos e livros didáticos. In: ABREU, Márcia (Org.). Leitura, história e história da leitura. Campinas, São Paulo: Mercado de Letras/ALB/FAPESP, 1999.

BITTENCOURT, Circe Maria Fernandes. Livro didático e saber escolar (1810-1910). Belo Horizonte: Autêntica, 2008.

CASSIANO, Célia Cristina de Figueiredo. O mercado do livro didático no Brasil do século XXI: a entrada do capital espanhol na educação nacional. São Paulo: Editora UNESP, 2013.

CHARTIER, Anne Marie. Práticas de leitura e escrita. História e Atualidade. Belo Horizonte: Autêntica, 2007.

CHARTIER, Roger. As revoluções da leitura no Ocidente. In: ABREU, Márcia. Leitura, história e história da leitura. São Paulo: ALB/FAPESP/Mercado de Letras, 2000.

CHARTIER, Roger. Do livro à leitura. In: CHARTIER, Roger (Org.). Práticas de leitura. São Paulo: Estação Liberdade, 1996.

CHARTIER, Roger. História cultural: entre práticas e representações. Lisboa: Difel, 1990.

CHOPPIN, Alain. História dos livros e das edições didáticas: sobre o estado da arte.

Educação e Pesquisa, São Paulo, v. 30, n. 3, p. 549-566, set./dez., 2004.

CHOPPIN, Alain. O historiador e o livro escolar. História da Educação, Pelotas, n. 11, p. 524, abril 2002.

CHOPPIN, Alain. O manual escolar: uma falsa evidência histórica. História da Educação, Pelotas, v. 13, n. 27, p. 9-75, jan./abr., 2009.

CHOPPIN, Alain. Políticas dos livros escolares no mundo: perspectiva comparada e histórica. História da Educação, Pelotas, v. 12, n. 24, p. 9-28, jan./abr., 2008.

CLAIR, Kate; BUSIC-SNYDER, Cynthia. Manual de tipografia: a história, a técnica e a arte. Porto Alegre: Bookman, 2009.

DARNTON, Robert. O beijo de Lamourette: mídia, cultura e revolução. São Paulo: Companhia das Letras, 2010.

DIETRICH, Mara Denise. Aspectos da vida profissional e da produção didática da professora Gilda de Freitas Tomatis. In: ENCONTRO DA ASSOCIAÇÃO SUL-RIOGRANDENSE DE PESQUISADORES EM HISTÓRIA DA EDUCAÇÃO - ASPHE, 17², 2011, Santa 
Maria/RS. Anais... Santa Maria: ASPHE, 2011, p. 1-15.

DIETRICH, Mara Denise. A Cartilha "Ler a Jato" e o "Método Audiofonográfico" de Alfabetização da professora Gilda de Freitas Tomatis (1967-1986). 2012. 234 f. Dissertação (Mestrado em Educação) - Faculdade de Educação/FaE, Universidade Federal de Pelotas/UFPel, Pelotas, 2012.

DIETRICH, Mara Denise; PERES, Eliane. A Cartilha Ler a Jato e o Método Audiofonográfico de Alfabetização em 15 horas: uma proposta da professora Gilda de Freitas Tomatis. In: CONGRESSO DE INICIAÇÃO CIENTÍFICA, XV; ENPOS, VIII - UFPel, 2006, Pelotas/RS. Anais... Pelotas/RS: UFPel, 2006, p. 1-4.

DIETZSCH, Mary Júlia. Cartilhas: um mundo de personagens sem texto e sem história. Cadernos de Pesquisa, São Paulo, n. 75, p. 35-44, nov. 1990.

FACIN, Helenara Plaszewski. Histórias e memórias da professora e autora de livros didáticos Nelly Cunha (1920-1999). 2008. 130 f. Dissertação (Mestrado em Educação) Faculdade de Educação/FaE, Universidade Federal de Pelotas/UFPel, Pelotas, 2008.

FACIN, Helenara Plaszewski; PERES, Eliane. Professora Nelly Cunha e a produção de livros didáticos. In: ENCONTRO DA ASSOCIAÇÃO SUL-RIO-GRANDENSE DE PESQUISADORES EM HISTÓRIA DA EDUCAÇÃO - ASPHE, 12 ${ }^{\circ}$, 2006, Santa Maria/RS. Anais... Santa Maria: ASPHE, 2006a, p. 1-15.

FACIN, Helenara Plaszewski; PERES, Eliane. Professora Nelly Cunha: história e memória. In: CONGRESSO INTERNACIONAL DE PESQUISA (AUTO)BIOGRÁFICA - CIPA, 2006, Salvador/BA. Anais... Salvador: UFB, 2006b, p. 1-18.

FACIN, Helenara Plaszewski; PERES, Eliane. Os livros didáticos produzidos no Rio Grande do Sul no período de 1960-1980 pela professora Nelly Cunha. In: SIMPÓSIO INTERNACIONAL "LIVRO DIDÁTICO: EDUCAÇÃO E HISTÓRIA", 2007, São Paulo/SP. Anais... São Paulo: USP, 2007, p. 1-15.

FACIN, Helenara Plaszewski; PERES, Eliane. Nelly Cunha: "sua vida foi escrever e ensinar, seu legado são seus livros didáticos". In: ABRAHÃO, Maria Helena Menna Barreto (Org.). Educadores Sul-rio-grandenses: muita vida nas histórias de vida. 1 ed. Porto Alegre: EDIPUCRS, 2008. p. 225-240.

\section{FERNANDES, Amaury. Fundamentos de produção gráfica para quem não é produtor} gráfico. Rio de Janeiro: Livraria Rubio, 2003.

FRADE, Isabel Cristina Alves da Silva. História da alfabetização e da cultura escrita: discutindo uma trajetória de pesquisa. In: MORTATTI, Maria do Rosário Longo (Org.). Alfabetização no Brasil: uma história de sua história. São Paulo/SP: Cultura Acadêmica, 2011. p. 177-199.

FRADE, Isabel Cristina Alves da Silva. Uma genealogia dos impressos para o ensino da escrita no Brasil no século XIX. Revista Brasileira de Educação, v. 15, n. 44, p. 264-407, maio/ago. 2010. 
FRADE, Isabel Cristina Alves da Silva. Materiais utilizados para ensinar a ler e escrever no Brasil: significado e pragmáticas. In: CASTELLANOS, Samuel Luis Velázquez; CASTRO, Cesar Augusto (Orgs.). Livro, leitura e leitor: Perspectiva Histórica. São Luís: Café \& Lápis; EDUFMA, 2016. p. 421-448.

FRADE, Isabel Cristina Alves da Silva; MACIEL, Francisca Izabel Pereira (Orgs.). História da alfabetização: produção, difusão e circulação de livros (MG, RS, MT, séculos XIX e XX). 1 ed. Belo Horizonte: CNPq/Fapemig/CEALE, 2006.

FUENTES, Rodolfo. A prática do design gráfico - uma metodologia criativa. São Paulo: Rosari, 2006. (Coleção Fundamentos do Design)

GALVÃO, Ana Maria; BATISTA, Antônio Augusto Gomes. Manuais Escolares e pesquisa em História. In: VEIGA, Cynthia Greive; FONSECA, Thaís Nívia de Lima e. História e historiografia no Brasil. Belo Horizonte: Autêntica, 2003.

GASPARELLO, Arlette Medeiros. Construtores de identidades: a pedagogia da nação nos livros didáticos da escola secundária brasileira. São Paulo: Iglu, 2004.

KURZ, Lúcia Edi dos Santos. A produção de cadernos-cartilhas por professorasalfabetizadoras pelotenses. 2006. 25 f. Monografia (Aperfeiçoamento - Especialização em Educação) - Universidade Federal de Pelotas, 2006.

LUKE, Allan. Literacy, textbooks and ideology: postwar literacy instruction and the mythology of Dick and Jane. Philadelphia: The Falmer Press, 1988.

LUPTON, Ellen; PHILLIPS, Jennifer Cole. Novos fundamentos do design. São Paulo: Cosac Naify, 2008.

MACIEL, Francisca Izabel Pereira; FRADE, Isabel Cristina Alves da Silveira. A história da alfabetização nas cartilhas escolares: práticas pedagógicas, produção e circulação em Minas Gerais, (1834-1997). In: CONGRESSO DE PESQUISA E ENSINO EM HISTÓRIA DA EDUCAÇÃO EM MINAS GERAIS, II, 2004, Uberlândia/MG. Anais... Uberlândia: EDUFU, 2004. p. 545-557.

MACIEL, Francisca Izabel Pereira. Lúcia Casasanta e o método global de contos: uma contribuição à história da alfabetização em Minas Gerais. 2001. 157 f. Tese (Doutorado em Educação) - Faculdade de Educação/FaE, Universidade Federal de Minas Gerais/UFMG, Belo Horizonte/MG, 2001.

MICHEL, Caroline Braga; PERES, Eliane; NOGUEIRA, Gabriela Medeiros. O(s) livro(s) de leitura Quieres leer? e Queres ler?: do Uruguai para o Rio Grande do Sul. In: ENCONTRO DA ASSOCIAÇÃO SUL-RIO-GRANDENSE DE PESQUISADORES EM HISTÓRIA DA EDUCAÇÃO - ASPHE, 19², 2013, Pelotas/RS. Anais... Pelotas: ASPHE/UFPEL, 2013, p. 945959.

MIRANDA, Carlos Eduardo Albuquerque. Orbis Pictus. Pro-Posições, v. 22, n. 3, p. 197-208, 2011. Disponível em: <http://www.proposicoes.fe.unicamp.br/ proposicoes/edicoes/texto 985.html . Acesso em: abril 2015. 
MOLLIER, Jean-Yves. Para uma abordagem transnacional do livro e da edição. In: CASTELLANOS, Samuel Luis Velázquez; CASTRO, Cesar Augusto (Orgs.). Livro, leitura e leitor: perspectiva histórica. São Luís: Café \& Lápis; EDUFMA, 2016. p. 39-56.

MONKS, Joseane Cruz; PERES, Eliane; THIES, Vania Grim. Títulos de livros para o ensino da leitura e da escrita como projeto enunciativo (1950-2006). In: ENCONTRO DA ASSOCIAÇÃO SUL-RIO-GRANDENSE DE PESQUISADORES EM HISTÓRIA DA EDUCAÇÃO ASPHE, 19², 2013, Pelotas/RS. Anais... Pelotas: ASPHE/UFPEL, 2013. p. 1166-1679.

MUNAKATA, Kazumi. Produzindo livros didáticos e paradidáticos. 1997. Tese (Doutorado em História e Filosofia da Educação) - Pontifícia Universidade Católica de São Paulo, São Paulo, 1997.

PANOFSKY, Erwin. Iconografia e Iconologia: Uma introdução ao estudo da arte da Renascença. In: Significado nas artes visuais. Tradução: Maria Clara F. Kneese e J. Guinsburg. 2 ed. São Paulo: Perspectiva, 1986. p. 47-65.

PERES, Eliane. A divulgação e a adoção do Método Global de ensino da leitura no Rio Grande do Sul (1940-1970). In: ENCONTRO DA ASSOCIAÇÃO SUL-RIO-GRANDENSE DE PESQUISADORES EM HISTÓRIA DA EDUCAÇÃO - ASPHE, IX, 2003, Porto Alegre/RS. Anais... Pelotas: Seiva/UFPel, 2003, p. 173-186.

PERES, Eliane. A produção e a circulação de cartilhas escolares no Rio Grande do Sul: alguns dados de pesquisa. In: FRADE, Isabel Cristina Alves da Silva; MACIEL, Francisca Izabel Pereira (Orgs.). História da Alfabetização: produção, difusão e circulação de livros (MG, RS, MT, séculos XIX e XX). 1 ed. Belo Horizonte: CNPq/Fapemig/CEALE, 2006a. p. 145170.

PERES, Eliane. A produção e o uso de livros de leitura no RS: Queres Ler e Quero Ler. História da Educação, Pelotas, n. 6, p. 89-103, out., 1999.

PERES, Eliane. Aspectos da produção didática da professora Cecy Cordeiro Thofhern. In: FRADE, Isabel Cristina Alves da Silva; MACIEL, Francisca Izabel Pereira (Orgs.). História da Alfabetização: produção, difusão e circulação de livros (MG, RS, MT, séculos XIX e XX). 1 ed. Belo Horizonte: CNPq/Fapemig/CEALE, 2006b. p. 171-190.

PERES, Eliane. Autoras de obras didáticas e livros para o ensino da leitura produzidos no Rio Grande do Sul: contribuições à história da alfabetização (1950-1970). Educação Unisinos, São Leopoldo/RS, v. 12, p. 111-121, 2008a.

PERES, Eliane. Desenvolvimento do projeto de pesquisa Cartilhas Escolares em Pelotas (RS): organização do trabalho, fontes e questões de investigação. In: FRADE, Isabel Cristina Alves da Silva; MACIEL, Francisca Izabel Pereira. (Orgs.). História da

Alfabetização: produção, difusão e circulação de livros (MG, RS, MT, séculos XIX e XX). 1 ed. Belo Horizonte: CNPq/Fapemig/CEALE, 2006c. p. 117-144.

PERES, Eliane. Influências do pensamento norte-americano na produção de cartilhas para o ensino da leitura e da escrita no Rio Grande do Sul na década de 1960. In: MORTATTI, Maria do Rosário Longo; FRADE, Isabel Cristina Alves da Silva (Orgs.). História do ensino 
de leitura e escrita: métodos e material didático. Marília: Editora da UNESP/Oficina Universitária, 2014. p. 93-120.

PERES, Eliane. Produção de cartilhas escolares no Rio Grande do Sul entre as décadas de 1950 e 1970: contribuições à história da alfabetização e das práticas escolares. In: ENCONTRO NACIONAL DE DIDÁTICA E PRÁTICA DE ENSINO - ENDIPE, XIV, 2008, Porto Alegre/RS. Anais... Porto Alegre: EDIPUCRS, 2008b, p. 1-12.

PERES, Eliane; ARRIADA, Eduardo. Fibel oder der Schereib-Lese-Unterricht. A. Haesters Fibel bearbeitet für die deutshen Shulen in Brasilien. In: GERT, GeiBler; SROKA, Wendelin; WOJDON, Joanna (Orgs.). Lesen Lernen... Mehrspraching. Fibeln und Lesebücher aus Europa und Amerika. Bonn/Essen: Alle Rechte bei den Herausgebern, 2011. p. 74-75.

PERES, Eliane; DIETRICH, Mara Denise. A Cartilha Ler a Jato e o Método Audiofonográfico: uma proposta da professora Gilda de Freitas Tomatis para o fim do analfabetismo no país. In: ENCONTRO DA ASSOCIAÇÃO SUL-RIO-GRANDENSE DE PESQUISADORES EM HISTÓRIA DA EDUCAÇÃO - ASPHE, 12º , 2006, Santa Maria/RS. Anais... Santa Maria: ASPHE, 2006, p. 115.

PERES, Eliane; DIETRICH, Mara Denise. A cartilha Ler a Jato e o método audiofonográfico: uma proposta de alfabetização de uma professora gaúcha para o fim do analfabetismo no país (décadas de 1960-70). In: BARCELOS, V. H. L.; ANTUNES, Helenise Sangoi (Orgs.). Alfabetização, letramento e leitura: territórios formativos. Santa Cruz do Sul: UNISC, 2010. p. 50-68.

PERES, Eliane; FACIN, Helenara Plaszewski. A produção didática da professora Nelly Cunha e suas contribuições para o ensino da leitura no Rio Grande do Sul (décadas de 1960-1980). In: SCHWARTZ, Cleonara; PERES, Eliane; FRADE, Isabel Cristina Alves da Silveira (Orgs.). Estudos de história da alfabetização e da leitura na escola. Vitória/ES: EDUFES, 2010. p. 137-170.

PERES, Eliane; PORTO, Gilceane Caetano. A produção e a circulação de cartilhas do Método Global de ensino da leitura no Rio Grande do Sul (décadas de 40-70). In: LEAHYDIOS, Cyana. (Org.). Espaços e tempos da educação - ensaios. 1 ed. Rio de Janeiro: C.L. Edições/BRASA, 2004. p. 26-40.

PERES, Eliane; RAMIL, Chris de Azevedo. A constituição dos acervos do Grupo de Pesquisa História da Alfabetização, Leitura, Escrita e dos Livros Escolares e sua contribuição para as investigações em educação. História da Educação, ASPHE/RS, v. 19, n. 47, p. 297-311, set./dez., 2015 a.

PERES, Eliane; RAMIL, Chris de Azevedo. Alfabetização pela imagem: uma análise das imagens da cartilha Caminho Suave e do material de apoio. In: CONGRESSO BRASILEIRO DE ALFABETIZAÇÃO - CONBALF, II, 2015, Recife/PB. Anais... Recife: Editora UFPE, 2015b, p. $1-15$.

PERES, Eliane; RAMIL, Chris de Azevedo. Alfabetização pela imagem: uma análise iconográfica da cartilha Caminho Suave e do material de apoio. Cadernos de Pesquisa em Educação, PPGE-UFES, Vitória/ES, v. 19, n. 41, p. 53-79, jan./jun., $2015 \mathrm{C}$. 
PERES, Eliane; RAMIL, Chris de Azevedo. Cartilhas produzidas por autoras gaúchas: um estudo sobre a circulação e o uso em escolas do Rio Grande do Sul (1940-1980). Versão Impressa e Versão Online. Revista Brasileira de Alfabetização, ABAlf, Vitória/ES, v. 1, n. 1, p. 177-203, jan./jun., 2015d.

PERES, Eliane; RAMIL, Chris de Azevedo. Os usos da Cartilha Caminho Suave em escolas gaúchas: um estudo em cadernos de alunos em fase de alfabetização. Revista Brasileira de Alfabetização, ABAlf, Vitória/ES, v. 1, n. 7, p. 103-131, jan./jun., 2018.

PERES, Eliane; TAMBARA, Elomar. Livros escolares e ensino da leitura e da escrita no Brasil (séculos XIX-XX). Pelotas: Seiva, 2003.

PERES, Eliane; VAHL, Mônica Maciel; RAMIL, Chris de Azevedo. Relações entre as autoras de cartilhas, as editoras e o estado no Rio Grande do Sul entre as décadas de 1940 a 1970. In: ENCONTRO DA ASSOCIAÇÃO SUL-RIO-GRANDENSE DE PESQUISADORES EM HISTÓRIA DA EDUCAÇÃO - ASPHE, 19², 2013, Pelotas/RS. Anais... Pelotas: ASPHE/UFPEL, 2013, p. $1150-1665$.

PERES, Eliane; VAHL, Mônica Maciel; THIES, Vania Grim. Aspectos editoriais da cartilha Caminho Suave e a participação da editora Caminho Suave Limitada em programas federais do livro didático. Revista Brasileira de História da Educação, Campinas/SP, v. 16, p. 335-372, 2016.

RAMIL, Chris de Azevedo Ramil. A coleção didática Tapete Verde: do projeto à sua produção gráfica (década de 1970 - Rio Grande do Sul). 2013. 223 f. Dissertação (Mestrado em Educação) - Faculdade de Educação, Universidade Federal de Pelotas, Pelotas, $2013 a$.

RAMIL, Chris de Azevedo Ramil. O circuito da produção de livros didáticos: o caso da coleção Tapete Verde (década de 1970). In: ENCONTRO DA ASSOCIAÇÃO SUL-RIOGRANDENSE DE PESQUISADORES EM HISTÓRIA DA EDUCAÇÃO - ASPHE, 19², 2013b, Pelotas/RS. Anais... Pelotas: UFPel, 2013b, p. 803-816.

RAMIL, Chris de Azevedo Ramil. Edições Tabajara: notas iniciais sobre as publicações didáticas e seus aspectos editoriais. In: ENCONTRO DE PÓS-GRADUAÇÃO UFPEL - ENPOS, XVI, 2014a, Pelotas/RS. Anais... Pelotas: UFPel, 2014a, p. 01-04.

RAMIL, Chris de Azevedo Ramil. Os livros didáticos e a linguagem visual gráfica: um estudo de caso dos anos 1970. In: ANPEDSUL - ASSOCIAÇÃO NACIONAL DE PÓSGRADUAÇÃO E PESQUISA EM EDUCAÇÃO / REGIÃO SUL, X, 2014, Florianópolis/SC. Anais... Florianópolis: UDESC/SC, 2014b. p. 01-21.

RAMIL, Chris de Azevedo Ramil. A coleção didática Tapete Verde: do projeto à sua produção gráfica (década de 1970 - Rio Grande do Sul). In: REUNIÃO NACIONAL DA ASSOCIAÇÃO NACIONAL DE PÓS-GRADUAÇÃO E PESQUISA EM EDUCAÇÃO - ANPED, $37^{a}$, 2015, Florianópolis/SC. Anais... Florianópolis: UFSC/SC, 2015a. p. 01-19.

RAMIL, Chris de Azevedo Ramil. Cartilha do Guri: um breve estudo das imagens. In: ENCONTRO DE PÓS-GRADUAÇÃO UFPEL - ENPOS, XVII, 2015, Pelotas/RS. Anais... Pelotas: UFPel, 2015b, p. 01-04. 
RAMIL, Chris de Azevedo Ramil. A iconografia e a iconologia nos livros didáticos das Edições Tabajara: um estudo das imagens na Coleção Guri (Rio Grande do Sul, década de 1960). 2018. 398 f. Tese (Doutorado em Educação) - Faculdade de Educação, Universidade Federal de Pelotas, Pelotas, 2018.

SILVA, Alexandra Lima da. Culturas letradas, experiência e ensino: uma análise a partir de livros didáticos de História do Brasil (1870-1924). Projeto História, São Paulo, n. 51, p. 140173, dez., 2014.

TAMBARA, Elomar. Trajetória e natureza do livro didático nas escolas de ensino primário no século XIX no Brasil. História da Educação, Pelotas, ASPHE/FaE-UFPel, n. 11, abr., 2002.

THIES, Vania Grim; VIEIRA, Cícera Marcelina. O acervo de livros estrangeiros para o ensino da leitura e da escrita do grupo de pesquisa HISALES. In: CONGRESSO BRASILEIRO DE ALFABETIZAÇÃO - CONBALF, II, 2015, Recife/PB. Anais... Recife: Editora UFPE, 2015, p. 0117.

VAHL, Mônica Maciel; VIEIRA, Cícera Marcelina; RAMIL, Chris de Azevedo; BORGES, Francieli D. Mapeando a produção didática de autoras gaúchas: relações entre o setor público e o privado (1940-1980). In: CONGRESSO LUSO-BRASILEIRO DE HISTÓRIA DA EDUCAÇÃO, X, 2014, Curitiba/PR. Caderno de resumos... Curitiba: PUCPR, 2014, p. 46.

VAHL, Mônica Maciel; VIEIRA, Cícera Marcelina; PERES, Eliane. Contratos de livros para o ensino da leitura e da escrita do Programa do Livro Didático para o Ensino Fundamental/PLIDEF (1972). HISTEDBR Online, Campinas/SP, v. 14, n. 58, p. 44-57, set., 2014.

VIEIRA, Cícera Marcelina. $O$ uso de cartilhas no processo de alfabetização: um estudo a partir de cadernos de planejamento de uma professora (1983-2000). 2014. $212 \mathrm{f}$.

Dissertação (Mestrado em Educação) - Faculdade de Educação/FaE, Universidade Federal de Pelotas/UFPel, Pelotas, 2014.

VIEIRA, Cícera Marcelina; MONKS, Joseane Cruz; VIEIRA, Fernanda Noguez. Cópias de atividades de cartilhas: o que revelam os cadernos de planejamento de uma professora alfabetizadora (1983-2000). In: ENCONTRO DA ASSOCIAÇÃO SUL-RIO-GRANDENSE DE PESQUISADORES EM HISTÓRIA DA EDUCAÇÃO - ASPHE, 19², 2013, Pelotas/RS. Anais... Pelotas: ASPHE/UFPEL, 2013. p. 548-563.

Universidade do Estado de Santa Catarina - UDESC

Programa de Pós-Graduação em Educação - PPGE

Revista Linhas

Volume 19 - Número 41 - Ano 2018 revistalinhas@gmail.com 